\title{
Estimation of local site effects in Ojiya city using aftershock records of the 2004 Mid Niigata Prefecture earthquake and microtremors
}

\author{
Hiroaki Yamanaka ${ }^{1}$, Kentaro Motoki ${ }^{1}$, Shun'ichi Fukumoto ${ }^{2}$, Toshiyuki Takahashi ${ }^{2}$, Nobuyuki Yamada ${ }^{3}$, and Kimiyuki Asano ${ }^{3}$ \\ ${ }^{1}$ Interdisciplinary Graduate School of Science and Engineering, Tokyo Institute of Technology, \\ 4259 Nagatsuta, Midori-ku, Yokohama, Kanagawa 226-8503, Japan \\ ${ }^{2}$ Tokyo Soil Research, 2-11-16 Higashigaoka, Meguro-ku, Tokyo 152-0021, Japan \\ ${ }^{3}$ Disaster Prevention Research Institute, Kyoto University, Gokasho Uji, Kyoto 611-0011, Japan
}

(Received February 15, 2005; Revised April 25, 2005; Accepted April 25, 2005)

\begin{abstract}
Aftershock observations of the 2004 Mid Niigata Prefecture earthquake were conducted in the central part of Ojiya city, the Niigata prefecture, central Japan, to investigate local site effects. We installed eight accelerographs in the vicinity of the K-NET and JMA stations in the area. The stations of the aftershock observations are situated under different geological conditions including one installed in a mountainous area on Tertiary layers to serve as a reference site. We examined the ground-motion characteristics of the records for a $\mathrm{Mj} 6.1$ aftershock focusing on local site effects. The amplification, at a period of less than $1 \mathrm{sec}$, is the largest in the vicinity of the K-NET station. The amplification at periods longer than $2 \mathrm{sec}$ is larger in the western part of the city than those in the east. We estimated the $S$-wave velocity structure in the sediments above the basement with an $S$-wave velocity of 3.4 $\mathrm{km} / \mathrm{sec}$ from the inversion of phase velocities measured by the array observations of vertical microtremors. We discuss the amplification factors using the $S$-wave velocity profile and show that shallow soils over the layer with an $S$-wave velocity of $0.49 \mathrm{~km} / \mathrm{sec}$ are responsible for the amplification at periods shorter than 0.4 sec. Deeper sedimentary layers are needed to explain amplification at periods of $1 \mathrm{sec}$.
\end{abstract}

Key words: 2004 Mid Niigata Prefecture earthquake, local site effect, aftershock observation, microtremor array exploration.

\section{Introduction}

The 2004 Mid Niigata Prefecture (Chuetsu) earthquake occurred on 23 October 2004 in the Niigata prefecture in central Japan. This was a shallow moderate earthquake (Mj 6.8) with many M6 aftershocks. Damage to buildings and wooden houses and landslides were observed in the vicinity of the fault. It was reported by the Japan Meteorological Agency (JMA) that the seismic intensities during the main shock were 6-upper and 7 in Ojiya city and Kawaguchi-machi, respectively. Strong ground motions of the main shock were recorded in Ojiya city by the K-NET and JMA. It was found from a quick analysis of the strong motion records that peak ground acceleration (PGA) and peak ground velocity (PGV) are approximately $1.4 \mathrm{G}$ and $1.3 \mathrm{~m} / \mathrm{sec}$ at the K-NET site in Ojiya city (Aoi et al., 2004). Although the ground motion was as large as those observed in the heavily damaged area of the 1995 Hyogoken-Nanbu earthquake, wooden houses and buildings did not always collapse in the vicinity of the K-NET site. To understand the damage distribution, variation of the ground-motion characteristics must be clarified. In particular, site amplification of the sedimentary layers should be properly estimated.

In this study, we analyzed the aftershock records to understand the site amplification factors in Ojiya city. We

Copy right(c) The Society of Geomagnetism and Earth, Planetary and Space Sciences (SGEPSS); The Seismological Society of Japan; The Volcanological Society of Japan; The Geodetic Society of Japan; The Japanese Society for Planetary Sciences; TERRAPUB. mainly used the records from the M6.1 aftershock on 25 October. We also conducted a microtremor array observation to explore the $S$-wave velocity structure in the city.

\section{Observation of Aftershocks}

The observation of the aftershocks was conducted from 26 to 30 October at eight temporary stations in Ojiya city (Fig. 1). The locations of the stations are also tabulated in Table 1. The station OJY01 is located in an eastern hilly area which is covered with Tertiary sandstone or gravel (Yanagisawa et al., 1986). We regarded this station as the reference site in the following analysis. The other stations are situated on Quaternary layers from west to east. It is noted that the surface geology for these sites on the Quaternary layers is classified in terrace deposits with gravel or sand (Yanagisawa et al., 1986). Our temporary stations were located around the stations of the K-NET and JMA, because one of our objects was to understand the differences in the strong ground motions observed during the main shock (e.g., Aoi et al., 2004).

A three-component accelerometer and a 14 bit-digital recorder were temporarily installed on the surface at each station. The instruments were continuously operated over several days using a battery. Recording started with a triggering signal generated by ground acceleration and continued for about $2 \mathrm{~min}$. The observations went on from the evening of 26 October until 10:00 on 29 October 2004. 

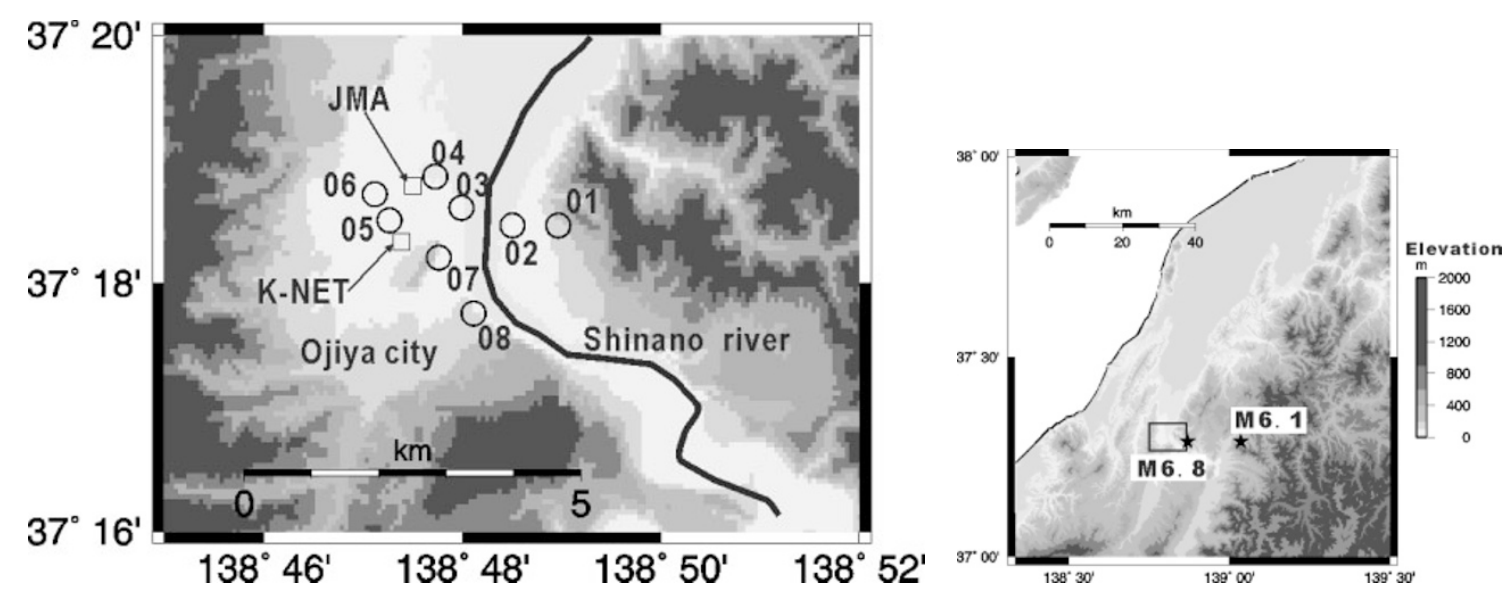

Fig. 1. Locations for stations in Ojiya city (left). Stars in the right figure show the locations of main shock and aftershock used in this study. The square area at the right indicates the area for the map on the left.

Table 1. Locations of aftershock observation stations in Ojiya city.

\begin{tabular}{clcc}
\hline Site code & \multicolumn{1}{c}{ Location } & Latitude & Longitude \\
\hline OJY01 & Hiu & 37.30779 & 138.81609 \\
OJY02 & Touei & 37.30782 & 138.80856 \\
OJY03 & Motomati & 37.31017 & 138.79983 \\
OJY04 & Jyounai, Ojiya city hall & 37.31433 & 138.79550 \\
OJY05 & Tsuchikawa & 37.30851 & 138.78773 \\
OJY06 & Sakuramachi & 37.31199 & 138.78532 \\
OJY07 & Funaoka & 37.30347 & 138.79603 \\
OJY08 & Yamamoto & 37.29599 & 138.80193 \\
\hline
\end{tabular}

\section{Analysis of Aftershock Records \\ 3.1 Estimation of site amplification}

One of the largest aftershocks (Mj 6.1) was observed in our aftershock observation stations at 10:40 (UT $+9 \mathrm{~h}$ ) on 27 October 2004. This is the aftershock whose fault plane is conjugate to that of the main shock (Kato et al., 2005). It is reported that the seismic intensity was 5-upper in Ojiya city and some houses that were damaged during the main shock collapsed. Ground velocities integrated from the acceleration records are displayed in Fig. 2 together with the records observed by the K-NET and JMA. The velocities in the figure were filtered over a period range of 0.1 to $10 \mathrm{sec}$. Unfortunately, no records are available from the station OJY07 during this event because of instrument troubles. It can be seen that high-frequency motion is dominant at the stations of K-NET, JMA, and OJY05. The high-frequency motion is not dominant at OJY06, although the station is only 0.5 $\mathrm{km}$ from OJY05. Furthermore, we can see a large $S$-wave pulse in the east-west component at all the sites. Figure 3 shows the particle motion of the ground velocities filtered in a period range from 1 to $5 \mathrm{sec}$. All the motions are dominant in the direction normal to the fault plane. This feature can be interpreted as the source effects of the fault rupture. Since all the stations are located in a similar azimuth from the epicenter in Fig. 1, the source effects is considered to be the same at all stations. In the following, we assumed that the variation of the ground motion was caused by local site effects.
Seismic intensities for the aftershock are calculated as shown in Fig. 4(a). The seismic intensity was at a maximum at the K-NET station and OJY05, while the smallest was about 4.8 at OJY03 and 04. A similar feature of the variation of the ground-motion characteristics can be seen in the distribution of the peak ground velocity (PGV) (Fig. 4(b)). The PGV at the K-NET station is 1.8 times larger than that at OJY07. The peak ground acceleration (PGA) in Fig. 4(c) shows a slightly different spatial variation: the largest PGAs are identified not only at the KNET and OJY05 sites but also at OJY02. These different features in the spatial variations of the seismic intensity, PGA, and PGV can be explained by different frequencydependent site amplifications. We therefore calculated the 2D pseudo-velocity response spectra with a damping of 5 percent, as shown in Fig. 5. The large peaks can be seen at periods of 0.4 to $0.5 \mathrm{sec}$ in the spectra at the K-NET and OJY05 stations where the seismic intensities are the largest. The spectrum at the JMA station has a shorter predominant period than those at the K-NET and OJY05 stations. A similar difference of the predominant periods can be found in the strong motion records at the K-NET and JMA stations (Aoi et al., 2004), although the predominant periods are different from those for the main shock because of the effects of nonlinear amplification of superficial soils. The spectra at the stations in the east of OJY04 are relatively flat when compared with that for the K-NET station. It is noted that the spectral amplitudes at periods of 2 to $3 \mathrm{sec}$ show a spa- 

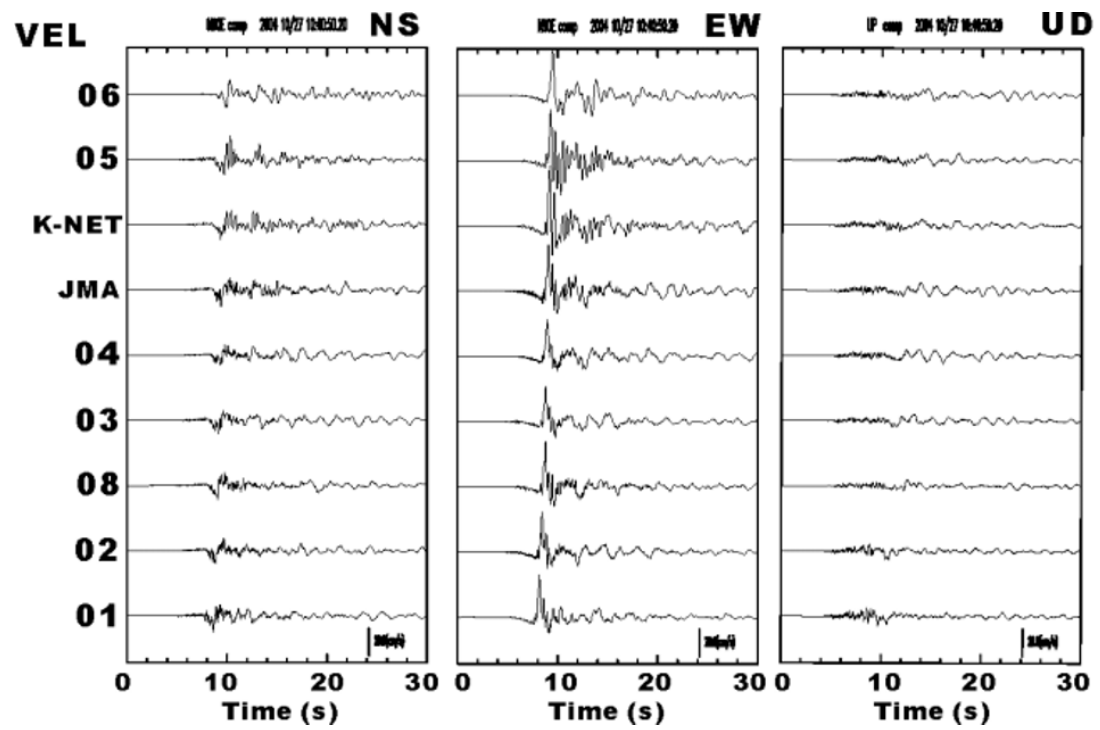

Fig. 2. Ground velocities of aftershock at 10:40 on 27 October with an Mj of 6.1. East-west (left), north-south (middle) and vertical (right) components are displayed. Each trace was calculated from integration of acceleration records with a band-pass filtering at periods from 0.1 to 10 sec.

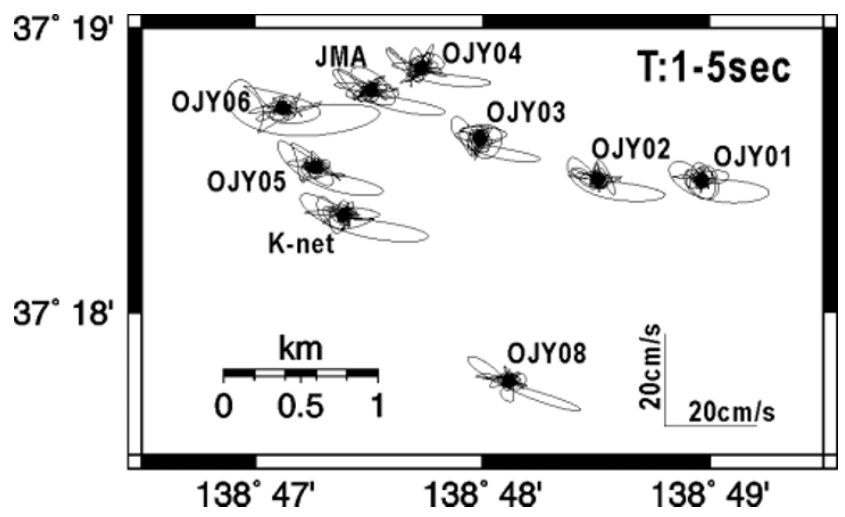

Fig. 3. Particle motion of horizontal ground velocity in a period range from 2 to $5 \mathrm{sec}$ for the aftershock at 10:40 (UT $+9 \mathrm{~h})$ of 27 October 2004.

tial variation where the amplitudes in the western part of the city (OJY05, 06, K-NET, and JMA stations) are larger than those in the east. In order to discuss these spatial variations of the local site effects, we calculated the Fourier spectral ratio of the horizontal motions at each station compared to that for OJY01. Figure 6 shows the distribution of the frequency-dependent spectral ratios with their peak periods. The ratios in the figure indicate the maximum value in each period range. The amplification in a short period range from 0.25 to $1 \mathrm{sec}$ is large at the OJY05 and K-NET stations, which is similar to that of the PGV. They can also be identified in the variation of the peak periods in Fig. 6(c). On the other hand, the amplifications at these sites are not large in the shorter periods of 0.1 to $0.25 \mathrm{sec}$. As pointed out by Aoi et al. (2004), the very shallow soils are responsible for the amplification in the short period range. This amplification in a period range from 2 to $5 \mathrm{sec}$ shown in Fig. 6(b) is large at the sites located in the west of the Shinano River, indicating the different effects of the deep subsurface structure. Thus, the local site amplification in Ojiya city is different in a)

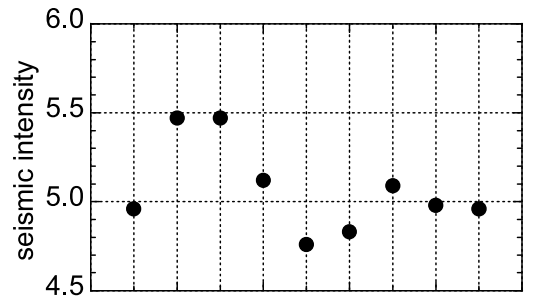

b)

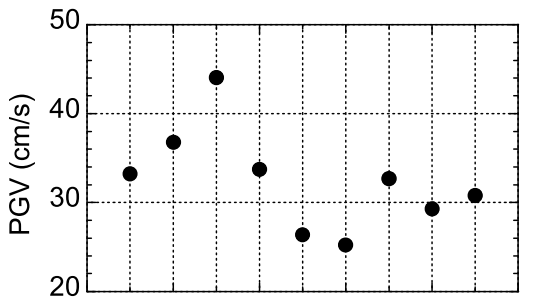

c)

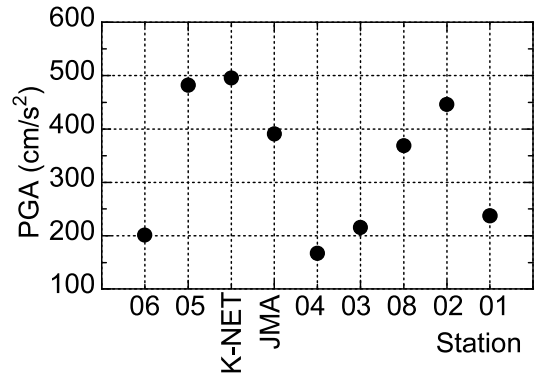

Fig. 4. Distributions of (a) seismic intensity, (b) PGV, and (c) PGA of horizontal motions for the Mj6.1 aftershock of 27 October 2004.

a wide period range and such effects should be included in the estimation of the strong ground motion during the main shock.

\subsection{Array analysis of later phases}

Further investigation into the ground motion characteristics at the K-NET station was conducted using a semblance analysis for the aftershock records observed at four stations (OJY05, 06, K-NET, and JMA). Figure 7 shows the results of the array analysis of the east-west component of the ground velocity. The upper trace is the filtered velocity 


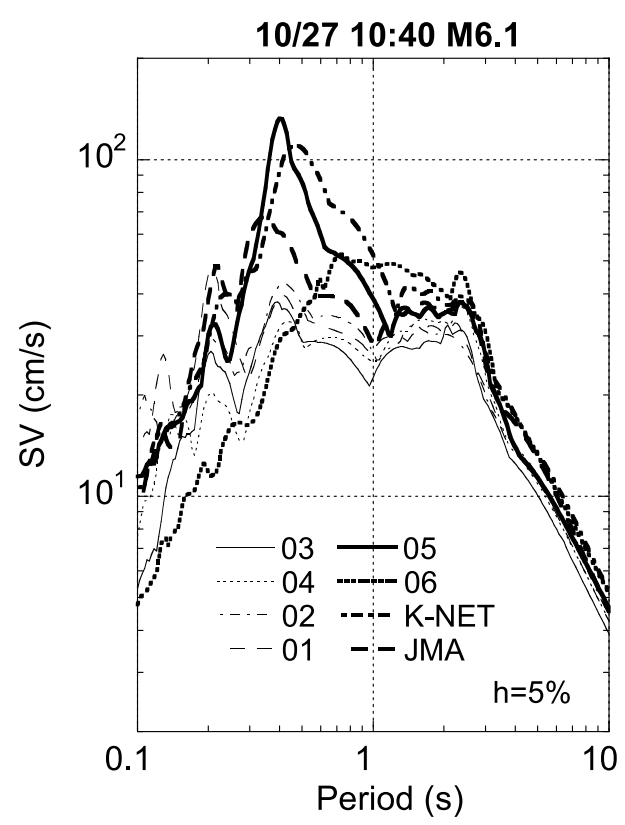

Fig. 5. Response spectra with a damping of 5 percent for the Mj6.1 aftershock of 27 October 2004.

a)

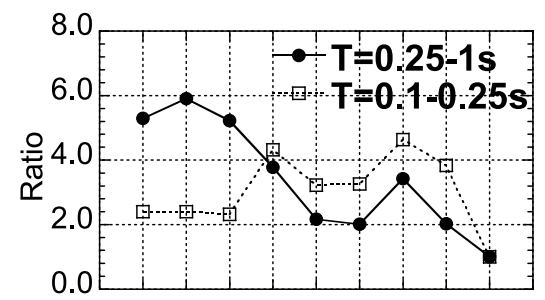

b)

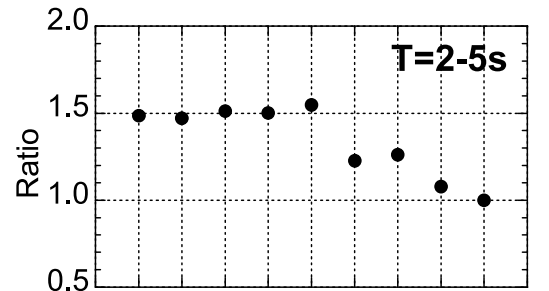

c)

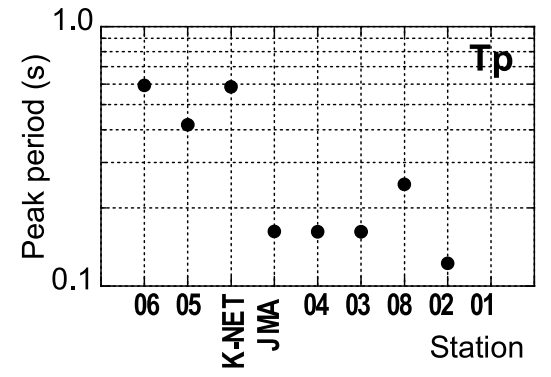

Fig. 6. Spectral ratios at periods of (a) 0.1 to $0.25 \mathrm{sec}$ and 0.25 to $1.0 \mathrm{sec}$, (b) 2 to $5 \mathrm{sec}$ together with (c) peak period.

at the K-NET station, and lower two indicate the slowness and propagation direction estimated in the semblance analysis. The propagation velocity is about $2 \mathrm{~km} / \mathrm{sec}$ and the propagation direction is the same as the epicentral azimuth for the initial $S$-wave part. This result clearly indicates that the initial $S$-wave part with a duration of $10 \mathrm{sec}$ can be explained by a $1 \mathrm{D}$ propagation of $S$-wave. However, the later phases at $30 \mathrm{sec}$ have a low velocity of about $0.8 \mathrm{~km} / \mathrm{sec}$. The propagation direction for the later phases is out of the a)

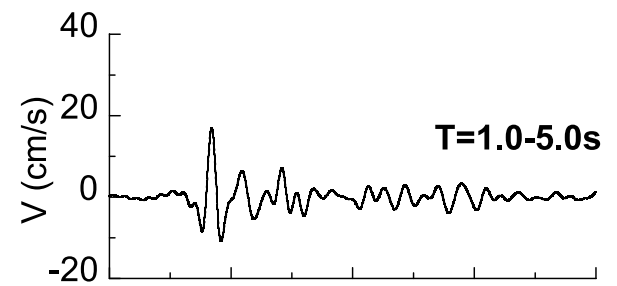

b)

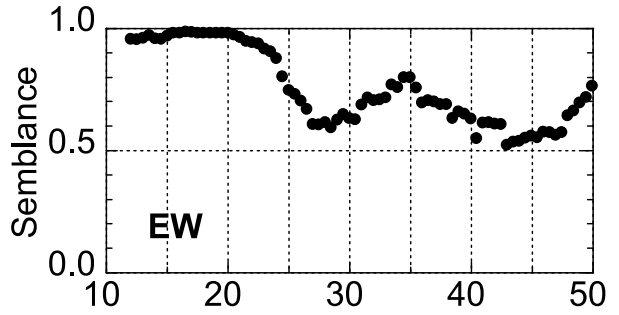

c)

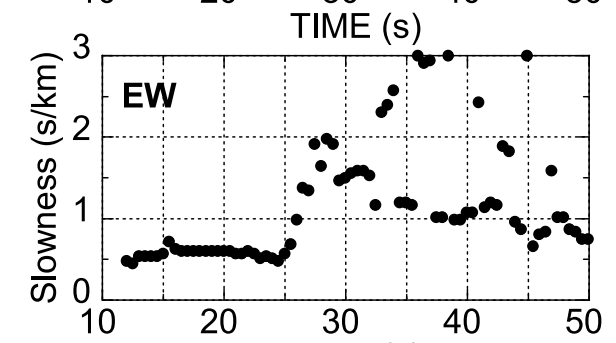

d)

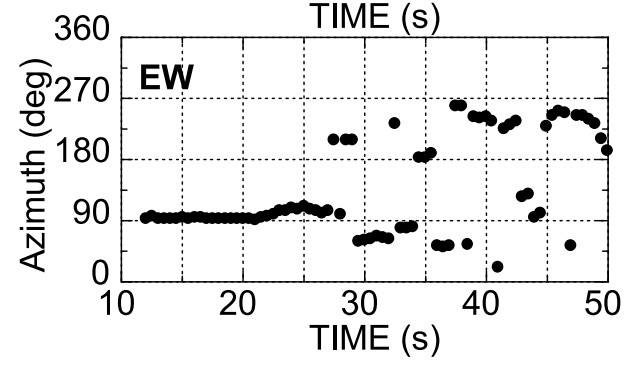

Fig. 7. Results of semblance analysis for the east-west oriented velocity for the Mj6.1 aftershock of 27 October 2004 in a period range from 1 to $5 \mathrm{sec}$. The trace in the top is (a) filter velocity, and lower three figures show (b) semblance, (c) slowness, and (d) the back azimuth estimated in the analysis.

epicentral direction, suggesting complex 3D effects of the sedimentary layers in the area.

\section{Estimation of $S$-wave Profile Using Mi- crotremors}

A microtremor array exploration was conducted in the area to estimate an $S$-wave profile down to the basement. We deployed temporary arrays of vertical seismometers to simultaneously observe vertical microtremors. The configurations of the arrays are depicted in Fig. 8(a). The large and middle arrays consist of stand-alone instruments that are synchronized with a GPS time signal, while three small arrays with four instruments are deployed in a circle with radii of 2,8 and $25 \mathrm{~m}$.

We applied frequency-wavenumber spectral analysis (Horike, 1985) to the vertical microtremors obtained in the large and middle arrays. For the data from the small arrays, a spatial-autocorrelation method (Okada, 2003) was used to estimate the phase velocity. Figure $8(\mathrm{~b})$ shows the phase velocity derived from the analysis. The phase velocity exhibits dispersive features in a wide period range from 0.1 to $5 \mathrm{sec}$. Therefore, we interpret it as the phase velocity of a 
a)

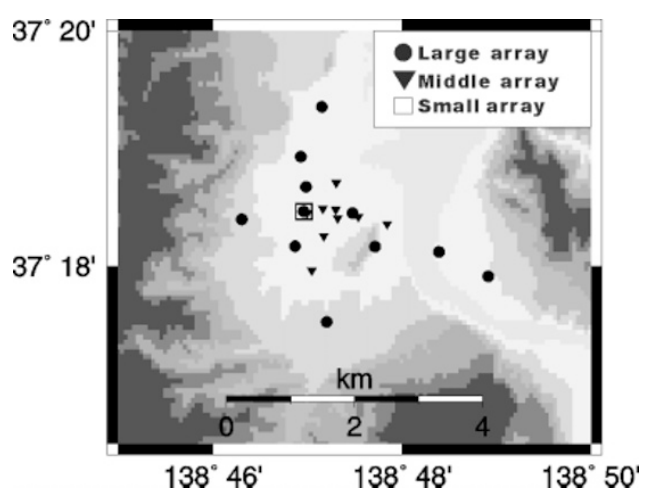

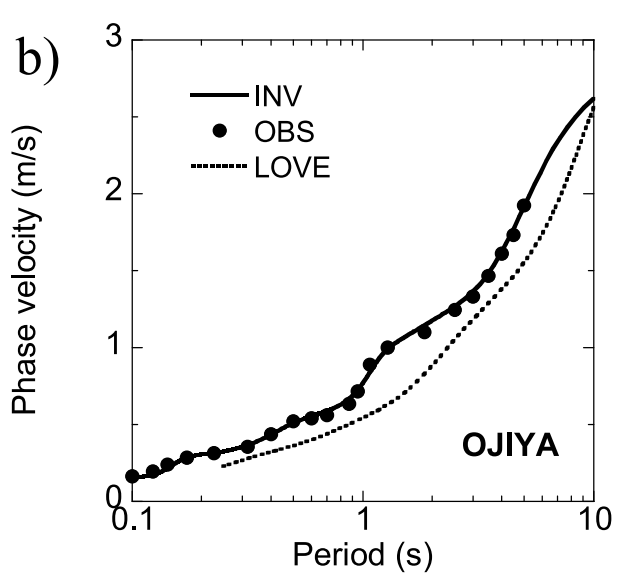

Fig. 8. Results of microtremor array exploration. (a) Locations of stations in temporary arrays. (b) Comparison of phase velocity obtained from microtremor array exploration (solid circle) with the calculated one (solid line) for the fundamental Rayleigh wave in the inverted $S$-wave profile shown in Table 2. The Phase velocity for fundamental Love wave is also shown by a broken line.

Table 2. Subsurface structure model estimated from microtremor array exploration in Ojiya city.

\begin{tabular}{cccc}
\hline$V s(\mathrm{~km} / \mathrm{s})$ & $V p(\mathrm{~km} / \mathrm{s})$ & Thickness $(\mathrm{km})$ & $\rho\left(\mathrm{kg} / \mathrm{m}^{3}\right)$ \\
\hline 0.15 & 1.46 & 0.01 & 1700 \\
0.34 & 1.67 & 0.04 & 1800 \\
0.49 & 1.83 & 0.05 & 1800 \\
0.65 & 2.01 & 0.21 & 2000 \\
1.22 & 2.64 & 0.64 & 200 \\
1.53 & 2.99 & 1.60 & 2100 \\
2.35 & 3.90 & 3.00 & 2500 \\
3.40 & 5.89 & - & 2700 \\
\hline
\end{tabular}

fundamental Rayleigh wave.

We next invert the phase velocity using the genetic algorithms of Yamanaka and Ishida (1996). In the inversion, the $S$-wave velocity and thickness for each layer are determined so as to fit the observed phase velocity with the calculated Rayleigh wave phase velocity. The $P$-wave velocity is calculated using an empirical relation with the $S$-wave velocity (Kitsunezaki et al., 1990) and the density is given in advance. We also assumed the $P$ - and $S$-wave velocities of the half-space. The inverted $S$-wave velocity is tabulated in Table 2. The theoretical phase velocity explains well the observed one, as compared in Fig. 8(b). The depth to the basement with an $S$-wave velocity of $3.4 \mathrm{~km} / \mathrm{sec}$ is more than $5 \mathrm{~km}$. The depth to one of the Tertiary sedimentary layers is reported to be more than $5 \mathrm{~km}$ around Ojiya city (Yanagisawa et al., 1986), which agrees with our results. In Fig. 8(b), the phase velocity for the fundamental Love wave is also shown. The Love wave phase velocity at periods around $2 \mathrm{sec}$ is about $0.8 \mathrm{~km} / \mathrm{sec}$ for the inverted model. This phase velocity of the Love wave is in good agreement with that estimated in the semblance analysis of the longperiod motion.

\section{Discussion}

We obtained an eight-layer model for the $S$-wave profile including the basement with an $S$-wave velocity of 3.4 $\mathrm{km} / \mathrm{sec}$ (Table 2). We then examined the effects of the $S$ - wave velocity of the bottom layer to estimate the amplification factors. The theoretical amplification factors were calculated by removing the lower layers and assuming that the bottom layer extends to infinity. Figure 9 shows the variation of the theoretical amplifications calculated for the models with different $S$-wave velocities of the half-space. In the calculation, Q-value is assumed to be $V s / 15$. The thin solid line indicates the amplification of the model with a bottom layer having an $S$-wave velocity of $3.4 \mathrm{~km} / \mathrm{sec}$ where the effects of all the sedimentary layers in the model in Table 2 are taken into account. The amplification shown by the thin dotted line is calculated for the model where the seventh layer with an $S$-wave velocity of $2.35 \mathrm{~km} / \mathrm{sec}$ is assumed as the half-space. Similarly, the thick solid line stands for the amplification for the model whose bottom layer has an $S$-wave velocity of $1.22 \mathrm{~km} / \mathrm{sec}$. The comparisons of the amplifications clearly indicates that the importance of top two low velocity layer in determining the amplification factors at periods shorter than $0.3 \mathrm{sec}$, because the peak at 0.25 sec can be seen in all the amplification. However, the spectral peak at $0.8 \mathrm{sec}$ is affected by deeper sediments over the layer with an $S$-wave velocity of $1.22 \mathrm{~km} / \mathrm{sec}$. Furthermore, we must consider the effects of much deeper layers in our estimation of the amplification at periods of longer than 1.0 $\mathrm{sec}$, because the five-layers model cannot generate a peak at $2.5 \mathrm{sec}$.

Figure 10 shows a comparison of the response spectra 


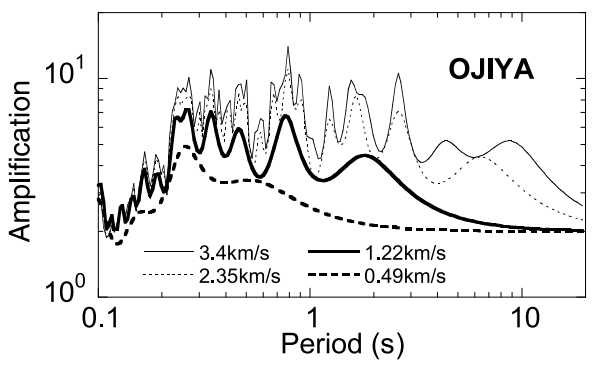

Fig. 9. Variation of amplification factors with different $S$-wave velocities for the bottom layer of the $S$-wave model shown in Table 2.

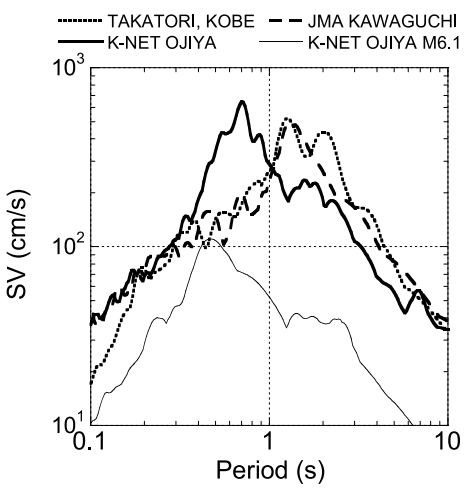

Fig. 10. Response spectra at the K-NET station in Ojiya for the main shock (thick solid line) and the Mj6.1 aftershock (thin line) on 27 October, 2004. Response spectra at Kawaguchi-cho (thick broken line) during the main shock and at Takatori (thick dotted line) during the 1995 Hyogo-ken Nanbu earthquake are also depicted.

(5\% damping) at the K-NET station in Ojiya city for the main shock and aftershock. Although the spectral peaks are identified at different periods because of the nonlinear effects of shallow soils (e.g., Aoi et al., 2004), the spectral shapes are very similar to each other. It is clearly indicated from our aftershock observation that the site amplification in the vicinity of the K-NET station is the largest in Ojiya city. Therefore, it is expected that the ground motion at the K-NET station was the most severe in the city during the main shock. The figure also compares the response spectrum observed at Kawaguchi-cho during the main shock together with the spectrum at Takatori during the 1995 Hyogo-ken Nanbu earthquake. The JMA seismic intensities at Kawaguchi-cho and Takatori were both 7 with heavy damage. The two spectra are larger at periods from 1 to $2 \mathrm{sec}$ than that in Ojiya city. It is indicated that the spectral amplitudes at this periods significantly affect the amount of structural damage (Aoi et al., 2004). This suggests one of probable reasons for the small damage in Ojiya city.

\section{Conclusions}

We conducted aftershock observations of the 2004 Mid

Niigata Prefecture (Chuetsu) earthquake in Ojiya city to investigate local site effects. The accelerometers were temporarily installed at eight sites in the central part of the city. We discussed the variation of the local site effects using the records from the Mj6.1 aftershocks occurring on 27 October 2004. The amplification in a period range of less than
$1 \mathrm{sec}$ was the largest at the K-NET station and the adjacent sites due to the superficial shallow soft soils. However, the amplification at periods longer than $1 \mathrm{sec}$ was larger in the western part of the city than those on the eastern side, suggesting the effects of the deep sedimentary layers. The semblance analysis of the aftershock records at the sites near the K-NET station indicated that the long-period later phases in an east-west direction are Love waves propagating in the sedimentary layers. The microtremor array exploration was conducted in the area to find out the $S$-wave profile down to the basement with an $S$-wave velocity of $3.4 \mathrm{~km} / \mathrm{sec}$. We discussed the amplification factors using the $S$-wave velocity profile and found that shallow soils over the layer with an $S$-wave velocity of $0.49 \mathrm{~km} / \mathrm{sec}$ are responsible for the amplification at periods shorter than $0.4 \mathrm{sec}$. Deeper sedimentary layers are needed to reproduce the amplification at periods of $1 \mathrm{sec}$.

Acknowledgments. The comments of E. Fukuyama, M. Horike and the anonymous reviewer were very helpful in improving the manuscript. We would like to thank Hitoshi Tanaka, Etsuko Yamada, Nobuhiko Komaba, Kaoru Ohtahara, and Kentaro Kasamatsu for the field observation. This study was supported by the Grant-in-Aid for Special Purposes (16800054), the Special Coordination Funds titled Urgent research on the Mid-Niigata prefecture Earthquake in 2004 of the Ministry of Education, Culture, Sports, Science and Technology (MEXT), and 21st Century Center of Excellence (COE) program titled Evolution of Urban Earthquake Engineering of the MEXT. A part of the ground motion data used in this study were provided by the K-NET of National Research Institute for Earth Science and Disaster Prevention and by the Japan Meteorological Agency and Japan Railway. Some of the figures were made using GMT (Wessel and Smith, 1991).

\section{References}

Aoi, S., N. Morikawa, R. Honda, H. Sekiguchi, T. Kunugi, and H. Fujiwara, Large ground-motion observed during the 2004 NiigatakenChuetsu earthquake, Summary on Reconnaissance Report of the 2004 Niigataken-Chuetsu Earthquake, Japan, Association for Earthq. Eng., 19-26, 2004 (in Japanese).

Hirata, N., H. Sato, S. Sakai, A. Kato, and E. Kurashimo, Fault system of the 2004 Mid Niigata prefecture earthquake and its aftershocks, Landslides, 2(2), doi:10.1007/s10346-005-0050-8, 2005.

Horike, M., Inversion of phase velocity of long-period microtremors to the $\mathrm{S}$-wave velocity structure down to the basement in urbanized areas, $J$. Phys. Earth, 33, 59-96, 1985.

Kato, A., E. Kurashimo, N. Hirata, T. Iwasaki, and T. Kanazawa, Imaging the source region of the 2004 Mid-Niigata prefecture earthquake and the evolution of a seismogenic thrust-related fold, Geophy. Res. Lett., 2005 (submitted)

Kitsunezaki, C., N. Goto, Y. Kobayashi, T. Ikawa, M. Horike, T. Saito, T. Kurota, K. Yamane, and K. Okuzumi, Estimation of P- and Swave velocity in deep soil deposits for evaluating ground vibrations in earthquake, J. Japan Soc. Natural Disaster Science, 9, 1-17, 1990 (in Japanese).

Okada, H., The microtremor survey method: Soc. Exp. Geophy., Tulsa, OK, 2003.

Wessel, P. and W. H. F. Smith, Free software helps map and display data, EOS, Trans. Amer. Geophys. U., 72, 441, 445-446, 1991

Yamanaka, H. and H. Ishida, Application of genetic algorithms to an inversion of surface-wave dispersion data, Bull. Seism. Soc. Am., 86, 436-444, 1996.

Yanagisawa, Y., I. Kobayashi, K. Takeuchi, M. Tateishi, K. Chihara, and H. Kato, Geology of the Ojiya district, Geological Survey of Japan, 1986 (in Japanese).

H. Yamanaka (e-mail: yamanaka@depe.titech.ac.jp), K. Motoki, S. Fukumoto, T. Takahashi, N. Yamada, and K. Asano 